\title{
Dietary risk factors amongst Singapore university students
}

\author{
S.K. Gill-Dang, L. Santos-Merx, F. Giam, D.Y.T Fung and M.Y. Chan \\ Food and Human Nutrition, Newcastle University in Singapore, Singapore
}

The National Health Survey ${ }^{(1)}$ reported that one in ten Singapore residents aged 18 to 69 years were obese (BMI $\left.\geqslant 30 \mathrm{~kg} / \mathrm{m}^{2}\right)$ and $23 \%$ were in the high risk Asian-BMI category $\left(B M I \geqslant 27 \mathrm{~kg} / \mathrm{m}^{2}\right)$. Presently, the prevalence of university students meeting national health guidelines is still relatively low $^{(2)}$ and healthy eating programs have been targeted more towards primary and secondary schools rather than tertiary institutions. This study aimed to investigate the nutritional intake of local university students compared to Singapore Recommended Dietary Allowances ${ }^{(3)}$.

The participants ( $\mathrm{n}=45$; aged 21 to 31 years) were recruited through convenience sampling and anthropometric measurements were taken at the start of the study. They were given food diaries to record their daily consumption of all three meals, snacks, and beverages over a 14-day period. Dietary records were analysed using WinDiets Nutritional Analysis Software. Nutrient information of local foods was derived from Health Promotion Board (HPB) 'Energy and Nutrient Composition of Food' Database ${ }^{(4)}$.

No significant correlation between BMI categories and total energy intake for both genders (females=24; males $=21$ ) was found using Spearman correlation test. Mean daily total energy intake in males $(1508 \mathrm{kcal} / \mathrm{day})$ and females $(1401 \mathrm{kcal} / \mathrm{day})$ were significantly lower (one sample t-test, $\mathrm{P}<0.0005$ ) than the RDA of $2200 \mathrm{kcal} /$ day and $1800 \mathrm{kcal} /$ day respectively ${ }^{(3)}$. The mean carbohydrate percentages of total energy intake in males $(46.91 \%)$ and females $(49.02 \%)$ were significantly lower $(\mathrm{P}<0.0005)$ than RDA of $55 \%{ }^{(3)}$. On the other hand, protein percentages of total energy intake in males $(19.01 \%)$ and females $(17.06 \%)$ and fat percentages of total energy intake in males $(33.40 \%)$ and females $(34.44 \%)$ were both significantly higher $(\mathrm{P}<0.0005)$ than the RDA of $13 \%$ and maximum of $30 \%$ respectively ${ }^{(3)}$. The mean saturated fat intake in males was $20 \mathrm{~g} /$ day (RDA $24 \mathrm{~g} / \mathrm{day}, \mathrm{P}<0.005$ ) and female mean intake was $19 \mathrm{~g} /$ day bordering the recommended limit of $20 \mathrm{~g} / \mathrm{day}^{(3)}(\mathrm{P}=0.335)$.

The fibre intake of participants was significantly lower than the recommended intake ${ }^{(3)}$ (figure 1). Even though the average male and female participants had significantly lower sugar intake than $55 \mathrm{~g}$ (figure 1), the HPB's recommended added sugar level of 40-55 g was recently critiqued to be too high and suggested to be revised to about $25 \mathrm{~g} / \mathrm{day}^{(5)}$. Interestingly, it was observed that sugar-sweetened beverage (SSB) intake was mainly habitual. Those who drank SSB were more likely to repeat their consumption more than once a week, while those who did not drink SSB, tended to consume plain water throughout the 14 days. Both genders showed significantly higher consumption of sodium (figure 1). This could be attributed to the nature of Asian cooking involving routine usage of sauces, broths and seasoning powders.
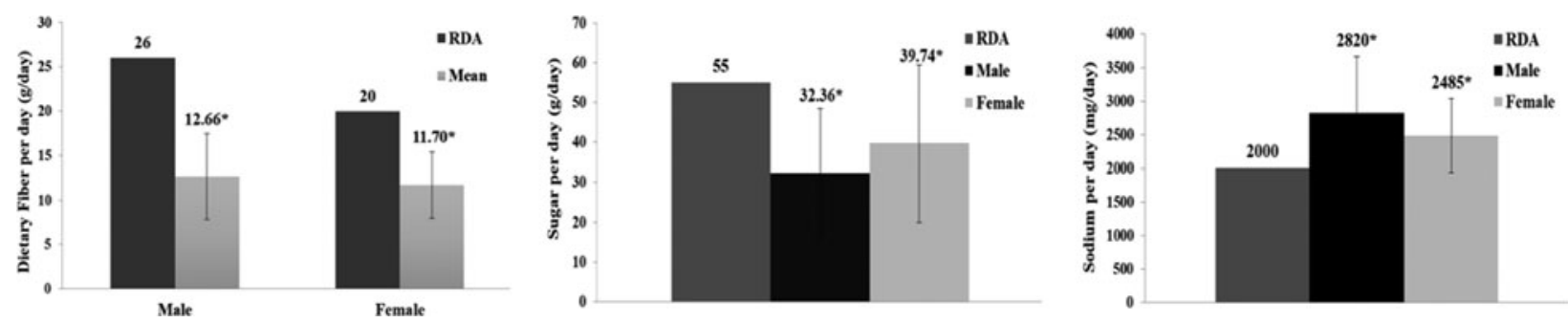

Fig. 1. Mean (SD) daily intake of fiber, added sugar, and sodium in males and females over a 14-day period. A one sample t-test $(\mathrm{P}<0.05)$ was used to test for significance compared to RDA values ${ }^{(3)}$.

A possible limitation of this study could be a reporting bias which might explain the significantly lower daily total energy intake amongst males and females. Nonetheless, the results from this exploratory study indicate a nutritional imbalance in these university students. It remains crucial to monitor dietary patterns of young adults as dietary habits can still be positively influenced by targeted healthy eating programs preventing the early onset of lifestyle-related non-communicable diseases.

1. Ministry of Health (2013) National Health Survey 2010 [cited 2018 April 8]. Available from: www.moh.gov.sg.

2. Lim RBT, Tham DKT, Müller-Riemenschneider F et al. (2017). Asia Pac J Public Health 29, 199-210.

3. Health Promotion Board (2003) Dietary Guidelines 2003 For Adult Singaporeans (18-65 years). Singapore: Health Promotion Board.

4. Health Promotion Board (2011) Energy and Nutrient Composition of food [cited 2018 April 8]. Available from: http://focos.hpb.gov.sg/eservices/ $\mathrm{ENCF} /$.

5. Ministry of Health (2017) WHO Sugar Guidelines [cited 2018 April 8]. Available from: www.moh.gov.sg. 